\title{
Knowledge, attitudes and practice of primary health care physicians towards hepatitis B virus in Al-Jouf province, Saudi Arabia
}

\author{
Ahmad H Al-Hazmi
}

\begin{abstract}
Background: Primary health care (PHC) physicians will be in the forefront of managing hepatitis B (HBV) patients. In Saudi Arabia, very little is known about knowledge, attitudes, and practice of PHC physicians towards HBV. This study aimed to assess the same parameters.

Methods: During April 2012, a cross-sectional survey of 180 practitioners aged $38.1 \pm 10.3$ years was carried out in the primary health care centers (PHCCS) in AlJouf Province of Saudi Arabia. The physicians were asked to fill a valid questionnaire containing their sociodemographic data, and well-modified questions regarding their knowledge base, attitudes, and practice towards HBV. Data was processed and analyzed using SPSS (version 17) program, the level of significance was set at $P<0.05$.

Result: Response rate $88.3 \%$ yielded 159 questionnaires for analysis. Majority of the physicians surveyed 128 (80.6\%) believed that PHC physicians are capable to achieve a major role in the management of HBV. 119 (74.8\%) physicians surveyed were willing to manage HBV patients and 127 (79.9\%) believed that vaccination is the most effective means to prevent HBV. There was a statistical significant correlation between physicians' qualifications and continuity of care for HBV patients (32.8\% vs $23.4 \% ; p=0.006$ ), while continuality of care was more frequent among physicians with higher degrees compared to graduate physicians. Only 69 (43.4\%) physicians were able to interpret HBV seromarkers. The vast majority of the physicians 142 (89.3\%) were willing to subscribe in regular training programs about HBV.

Conclusion: Suitable attitudes with lack of knowledge are found, and practice of our physicians with regard to this significant health issue appeared inappropriate. More education focusing on HBV is recommended.
\end{abstract}

Keywords: Attitudes, Continuity of care, Hepatitis B, Knowledge, Primary health care, Saudi Arabia

\section{Background}

Hepatitis B virus (HBV) represents important, yet clinically silent public health significance worldwide [1]. World health organization (WHO) data estimate serologic evidence of past or present HBV infection among two billion persons globally, while over 350 million people are carriers of chronic hepatitis $\mathrm{B}(\mathrm{CHB})$ worldwide [1,2]. The virus is transmitted in the blood and fluids which can be diagnosed during acute and chronic stages [3]. Acute infection may cause nonspecific symptoms or fulminant hepatitis that may die or requires urgent liver transplantation [3].

Correspondence: dr.ahmad-medical@hotmail.com

Department of Family Medicine, College of Medicine, AlJouf University, King Khalid road, Al-Jouf, P.O. Box 2014, Sakaka 75741, Saudi Arabia
Chronic infection with HBV causes death associated with cirrhosis, liver failure, or hepatocellular carcinoma, and has a negative impact on health-related quality of life (HRQOL) [2-4]. HBV ranks second, after tobacco, on the list of known carcinogenic agents affecting humans and the tenth leading cause of death globally $[5,6]$. Costs associated with HBV are therefore substantial; it creates a significant economic burden to the health care services $[1,4,7]$.

PHC physicians will be in the forefront of managing patients with chronic hepatitis B infection and most hepatitis $B$ infections are identified at the primary care level $[8,9]$. It is assumed that physicians practicing in our community are lacking the important knowledge about 
and the appropriate attitudes toward HBV. Although, many studies in different countries have evaluated the knowledge level, attitudes, and practice among PHC physicians towards HBV [9-11]. There have been a very few attempts to identify a specific impact of this condition among physicians practicing in Saudi Arabia, a country with the highest high endemicity of HBV [12]. Hence, the main reasons of this study are to evaluate the knowledge base, attitudes, and to explore practice patterns of PHC physicians towards HBV. The data and information obtained from this study will identify weaknesses and help to improve healthcare system in managing this serious disease in the primary care setting.

\section{Methods}

\section{Study design and setting}

A cross-sectional descriptive study was carried out on physicians practicing at PHCCs in AlJouf province of Saudi Arabia (population $3.5 \times 10^{5}$ ). The province contains four towns Domat alJanddal, Zallom, Sowair and Sakaka. There were around 200 physicians practicing in a total 45 PHCCs. Out of these 45, forty PHCCs were selected for the present study.

\section{Questionnaire}

The well-structured questionnaire was developed to assess the KAP of PHC physicians regarding HBV. The study questions and the characteristics of participants were based on previous surveys and articles with similar objectives [7-11,13-15]. For validating the questionnaire, specific experts in standardizing questionnaire, gastroenterologists, hepatologists, community medicine and biostatistics, confirmed the introduction and validity contents of the primary questionnaire. Some questions were omitted according to their advice. The questionnaire comprised of 39 "closed ended questions". The first part contained 33 with variable items (3-15) focusing on physicians' knowledge, attitudes, and the most importantly, clinical points in the management of this condition [1-3,7-9]. The second part covered demographic characteristics of physicians (age, gender, graduation level, years in practice, type of job, and nationalities). The study protocol was discussed and approved by the research and ethical committee in AlJouf University College of Medicine.

During April 2012, 180 self-administered anonymous confidential questionnaires with explanatory letters were distributed to the PHC physicians practicing in 40 PHCCs. We started with meeting the director of the centre and giving a ten minutes introduction, explaining objectives of the study and going through all the questions with the physicians. The physicians were then asked to fill the questionnaires in their clinics and return them back to the investigator in same day.
On $15^{\text {th }}$ march 2012, the questionnaire was pre-tested during a pilot study that was conducted in 8 PHCCs inside Sakaka city. This was done to ensure clarity, relevance and to determine the amount of time needed to answer all items. The result of the pre-test was evaluated critically and some modifications were made accordingly. The average time needed to fill all items in the questionnaire was about 25 minutes. Results of the pilot study were not included in the final analysis.

\section{Statistical analysis}

Data were analyzed using SPSS packed version 17.0 (IBM SPSS Inc., Chicago, IL, USA). $p<0.05$ was considered significant; Chi-square test was applied for analysis of categorical data. Mean \pm SD and proportions were used to describe continuous and dichotomous data, respectively.

\section{Results}

Out of the 180 questionnaires distributed, 159 (response rate: $88.3 \%)$ were collected and analyzed. The general characteristics of physicians are shown in Table 1. A majority of the physicians were males 128 (80.5\%), and the number of the female physicians was only $31(19.5 \%)$. The male to female ratio was found to be 4.1:1; with mean \pm SD age were $38.1 \pm 10.3$ years (range 27 to 65 years). Physicians with $\geq 10$ years of practice constituted less than half of the sample $76(47.8 \%)$. Less than half of the physicians 59 (37.1\%) had post graduate degrees, and only 9 (5.7\%) were Saudi nationals. Of the physicians surveyed, 43 (27\%) see an average of $3 \mathrm{HBV}$ patients per week, 25 (15.7\%) diagnose an average of less than 5 HBV patients per month. Whereas, 23 (14.5\%) refer an average of 3 patients per month.

When asked about what would they do if a patient with HBV presents to their office, we found only $30.8 \%$ $(n=45)$ of the physicians responded that they will achieve continuity of care for HBV; whereas $62.9 \%(n=100)$ of the participants will refer HBV immediately or later to the specialists. Four males and three female physicians (4.4\%) were not sure what should be done for HBV.

When inquired about whether the PHC physicians are capable to achieve a major role in the management of HBV; 85 (53.5\%) agreed, 43 (27.1\%) strongly agreed, $13(8.2 \%)$ disagreed, 4 (2.6\%) strongly disagreed, and $12(7.7 \%)$ were not sure.

Table 2 presents physicians' correct answer rates on knowledge about HBV distributed by their qualifications. It is obvious that in each area the mean proportion of the correct answers varied. Overall, the mean knowledge level among the physicians surveyed was $62.9 \%$, (range 28.9 to $88.1 \%$ ). The maximal ranking was pertaining to the physicians' knowledge about an acute infection may cause nonspecific symptoms and the minimal ranking was pertaining to their knowledge about the number of 
Table 1 Distribution of primary health care physicians according to their general characteristics

\begin{tabular}{ll}
\hline Characteristics & $\begin{array}{c}\text { Primary health care physicians } \\
(\mathrm{N}=159)\end{array}$ \\
\cline { 2 - 3 } & No $\quad \%$
\end{tabular}

Gender:

- Male

- Female

Type of job

- Governmental

- Private

Age

- $<30$ years

- 30-40 years

- 41-50 years

- 51-60 years

Post-graduate Qualifications:

- MBBS

- Diploma

- Master Degree

- Board or PhD

Years in practice:

- $\leq 5$ years

- $>5-10$ years

- >10-20 years

- >20-30 years

- >30 years

Nationalities:

- Saudi

- Egyptians

- Sudanese

- Syrian

- Jordanian

- Indian

- Pakistani

- Bangladeshi

- Other nationalities
HBV serotypes. There were no statistical significant correlations between physicians' qualifications and their knowledge about HBV in all items.

Table 3 shows physicians' attitudes toward HBV. The study has shown that, 106 (66.7\%) physicians did not have concern on shaking hands with a person who has HBV and 108 (67.9\%) physicians did not feel uncomfortable hugging him. Having a person with $\mathrm{CHB}$ in the same workplace was accepted by only $62(39.0 \%)$ physicians. The vast majority 139 (85.5\%) were willing to get more training programs about $\mathrm{HBV}$ and suggested to establish "Saudi guidelines to care and manage HBV patients".

Table 4 shows physicians' responses on different aspects of practice toward HBV. By the findings it is revealed that 119 (74.8\%) physicians would take care of HBV patient. Most of the physicians ( $\mathrm{n}=139 ; 87.4 \%)$ were willing to collaborate with other health professionals, especially trained nurses, dieticians, and hepatologists on management of HBV patients. Of all the physicians surveyed, only 7 (4.4\%) prescribe some forms of complimentary medications for HBV patients.

Table 5 shows physicians' knowledge on HBV vaccine distributed by their years in practice. Only 63 (39.6\%) physicians surveyed recognized that the duration of protection is at least 15 years after receiving 3 doses of $\mathrm{HBV}$ vaccine and, based on current scientific evidence, lifelong. Also, $80(50.3 \%)$ of the sample regarded pregnancy is contraindication for use of this vaccine.

Regarding the possible modes for HBV transmission, 142 (89.3\%) physicians reported through wound-towound, 140 (88.1\%) sexual contact, 127 (79.9\%) during delivery from the infected mothers to their infants, 110 (69.2\%) maternofetal, 83 (52.2\%) through saliva followed by $81(50.9 \%)$ breast milk. While, $130(81.8 \%)$ physicians considered hugging, 136 (85.5\%) shaking hands or 123 (77.4\%) sharing foods with infected persons as a safe practices.

When asked about the main sources of their knowledge about HBV; textbooks were ranked first among 139 (85.5\%) physicians, followed by internet 15 (9.4\%), whereas medical journals were the main sources among 8 (5.0\%) physicians.

\section{Discussion and conclusion}

Hepatitis B virus is a challenging infectious disease for all of the health care professionals throughout the world [1-3]. Fortunately, infection with this virus is not only treatable, but also preventable [2-5]. PHC physicians are, thus, expected to achieve a major role in the diagnosis, prevention, and referral of HBV, as a means of controlling HBV [7-11]. The current study is, to the best of the author's knowledge, the first comprehensive PHC settingbased survey carried out in Saudi Arabia (alJouf province) to evaluate knowledge, attitudes and practice of PHC physicians regarding management of $\mathrm{HBV}$ in the PHCCs. We believe that our sample was representative of the PHC physicians and accounted for approximately $80 \%$ of all the PHC physicians practicing in alJouf province. More than half the physicians under this study had low to moderate experience in PHC setting ( $\leq 10$ years).

This study, clearly, proves that physicians practicing in our community were aware of magnitude of HBV in Saudi Arabia [12]. It is found, most of the physicians 102 
Table 2 Physicians' knowledge about HBV in relation to their qualifications (correct answer rates)

\begin{tabular}{|c|c|c|c|c|c|c|c|}
\hline \multirow[b]{2}{*}{ Question item: (correct answer) $¥$} & \multirow[b]{2}{*}{$\begin{array}{c}\text { Correct; } \\
\mathrm{n}=159(\%)\end{array}$} & \multicolumn{4}{|c|}{ PHC physicians' qualifications } & \multirow[b]{2}{*}{$x^{2}$} & \multirow[b]{2}{*}{$\begin{array}{c}P \\
\text { value }\end{array}$} \\
\hline & & $\begin{array}{l}\text { MBBS; } \\
(n=96)\end{array}$ & $\begin{array}{l}\text { Diploma, } \\
(n=23)\end{array}$ & $\begin{array}{l}\text { Masters degree, } \\
\quad(n=29)\end{array}$ & $\begin{array}{l}\text { Board or PhD } \\
(n=11)\end{array}$ & & \\
\hline Acute infection may cause nonspecific symptoms; (T) & $140(88.1)$ & $89(92.7)$ & $19(82.6)$ & $24(82.8)$ & $8(72.7)$ & 7.126 & 0.129 \\
\hline $\begin{array}{l}\text { Chronic infection is characterized by persistence of HBsAg } \\
\text { (with or without concurrent } \mathrm{HBeAg} \text { ); ( }>6 \text { months). }\end{array}$ & $96(60.4)$ & $60(62.5)$ & $13(56.5)$ & $18(62.1)$ & $5(45.5)$ & 14.577 & 0.556 \\
\hline $\begin{array}{l}\text { Chronic infection will develop in almost all children } \\
\text { infected perinatally; }(T)\end{array}$ & $64(40.3)$ & $39(40.6)$ & $8(34.8)$ & $13(44.8)$ & $4(36.4)$ & 9.139 & 0.331 \\
\hline $\begin{array}{l}\text { Transmission after needlestick is higher for HIV in } \\
\text { comparison with HBV; (F) }\end{array}$ & $89(56.0)$ & $54(56.3)$ & $9(39.1)$ & $20(69.0)$ & $6(54.5)$ & 8.711 & 0.367 \\
\hline $\begin{array}{l}\text { Seven genotypes of HBV have been identified labeled A } \\
\text { through G; }(F)\end{array}$ & $46(28.9)$ & $22(22.9)$ & $9(39.1)$ & $10(34.5)$ & $5(45.5)$ & 15.618 & 0.209 \\
\hline $\begin{array}{l}\text { Mothers who are both } \mathrm{HBs} A g \text { and hepatitis B "} \mathrm{e} " \text { antigen } \\
\text { (HBeAg)-positive pass the virus perinatally to } 70 \% \text { to } 90 \% \\
\text { of their offspring; (T) }\end{array}$ & $123(77.4)$ & $72(75.0)$ & $18(78.3)$ & $24(82.8)$ & $9(81.8)$ & 5.085 & 0.748 \\
\hline $\begin{array}{l}\text { Treatment for chronic viral hepatitis } B \text { is very expensive } \\
\text { and not always effective; }(T)\end{array}$ & $119(74.8)$ & $71(74.0)$ & $14(58.3)$ & $24(82.8)$ & $10(90.9)$ & 10.275 & 0.246 \\
\hline $\begin{array}{l}\text { The most effective means to prevent HBV infection is } \\
\text { through vaccination; }(T)\end{array}$ & $127(79.9)$ & $77(80.2)$ & $18(78.3)$ & $24(82.8)$ & $8(72.7)$ & 5.812 & 0.668 \\
\hline HBV replicates only hepatocytes; (T) & $97(61.0)$ & $54(56.3)$ & $15(65.2)$ & $21(72.4)$ & $7(63.6)$ & 9.117 & 0.693 \\
\hline
\end{tabular}

¥ Some physicians did not respond to some items in some questions; $H B V$ - Hepatitis $B$ virus; $T=$ true, $F=$ false.

(64.2\%) perceived that HBV at level of public health significance in the country; and 131 (82.4\%) suggested the need of catch-up vaccination for all Saudi older age groups, including adolescents and adults. Also, 143 (89.9\%) suggested "educational strategies about HBV with special attention to Saudi citizens of lower education levels and lower socio-economic classes". Our findings are in agreement with, and support, recommendations and reports of CDC about HBV [13]. The referred recommendations and reports demonstrate that more actions should be offered to HBV in the highly endemic areas like Saudi Arabia where HBV prevalence is $\geq 8 \%[12,13]$.

It is well documented that most patients with chronic HBV are identified in the primary care level and only those with chronic active HBV are selected for specialist care $[9,10,14]$. Unfortunately, we found only 45 (28.3\%) physicians surveyed will carry a continuity of care for HBV patients; whereas, 99 (62.3\%) will refer HBV to the specialists. However, an effective referral is needed only for those who are eligible for sophisticated diagnosis and antiviral therapy $[9,10,14]$. Our findings are in agreement with those practical difficulties in the management of HBV in Asia-Pacific [7]. The referred reports have demonstrated that $\mathrm{PHC}$ physicians may show a reluctance to treat HBV patients, because of incomplete knowledge about hepatitis $B$, resulting in the referral of numerous patients to specialists [7]. Also, lack of suitable approach or confidence with lack of diagnosis facilities all contribute to referral $[7,11]$.

This study shows inadequate knowledge among PHC physicians regarding $\mathrm{HBV}$, but this not necessarily reflects the picture of PHC physicians who are practicing

Table 3 Primary health care physicians' attitudes toward HBV ( $N=159)$

\begin{tabular}{|c|c|c|c|c|c|}
\hline Attitudinal item & $\begin{array}{c}\text { Strongly disagree; } \\
\text { N (\%) }\end{array}$ & $\begin{array}{l}\text { Disagree; } \\
\text { N (\%) }\end{array}$ & $\begin{array}{l}\text { Neutral; } \\
\text { N (\%) }\end{array}$ & $\begin{array}{l}\text { Agree; } \\
\text { N (\%) }\end{array}$ & $\begin{array}{c}\text { Strongly } \\
\text { agree; } \mathrm{N}(\%)\end{array}$ \\
\hline I have concern to get HBV from my patients & $19(11.9)$ & $30(19.0)$ & $30(19.0)$ & $67(42.1)$ & $13(8.2)$ \\
\hline I would not mind having a person infected with HBV in my working place & $22(13.8)$ & $42(26.4)$ & $33(20.8)$ & $49(30.8)$ & $12(7.6)$ \\
\hline I have concern in shaking hands of persons infected with HBV infection & $46(28.9)$ & $60(37.7)$ & $27(17.0)$ & $16(10.1)$ & $9(5.7)$ \\
\hline I would feel uncomfortable hugging a person who has HBV & $38(23.9)$ & $70(44.1)$ & $17(10.7)$ & $29(18.2)$ & $5(3.1)$ \\
\hline Chronic infection with HBV is shameful & $65(40.9)$ & $54(34.0)$ & $23(14.5)$ & $13(8.2)$ & $3(1.9)$ \\
\hline It is difficult to eradicate HBV & $12(7.6)$ & $42(26.4)$ & $35(22.0)$ & $53(33.3)$ & $17(10.7)$ \\
\hline More attention should be offered to HBV & $15(9.4)$ & $5(3.2)$ & $7(4.4)$ & $72(45.3)$ & $60(37.7)$ \\
\hline I wish to get more training programs about HBV & $10(6.3)$ & $2(1.3)$ & $10(6.3)$ & $59(37.1)$ & $76(48.0)$ \\
\hline Can participate in all activities including contact sports & $6(3.8)$ & $23(14.5)$ & $28(17.6)$ & $74(46.5)$ & $26(16.4)$ \\
\hline
\end{tabular}


Table 4 Practices of primary health care physicians towards HBV: Options in the management of patients with HBV include the following as needed

\begin{tabular}{|c|c|c|c|}
\hline In your clinic; options in care of patients with HBV include the following as needed: ₹ & Do N (\%) & Don't N (\%) & Don't know N (\%) \\
\hline I would take care of an infected-person with HBV & $119(74.8)$ & $24(15.1)$ & $14(8.8)$ \\
\hline Persons with chronic HBV infection should be monitored for disease activity & $142(89.3)$ & $7(4.5)$ & $7(4.5)$ \\
\hline Sexual partners should be immunized & $145(91.0)$ & $11(7.1)$ & $3(1.9)$ \\
\hline Involvement of the family in education of persons infected with HBV & $143(90.0)$ & $10(6.3)$ & $6(3.8)$ \\
\hline All medications should be taken under physician instructions & $146(91.8)$ & $7(4.5)$ & $6(3.8)$ \\
\hline Irregular food regimens can worsen HBV infection & $79(49.7)$ & $53(33.3)$ & $27(17.1)$ \\
\hline Not share toothbrushes or razors & $141(88.7)$ & $11(7.1)$ & $7(4.5)$ \\
\hline $\begin{array}{l}\text { Persons with chronic HBV infection who are not immune to hepatitis A should } \\
\text { receive two doses of hepatitis } A \text { vaccine at least six months apart }\end{array}$ & $91(57.2)$ & $30(18.9)$ & $38(23.9)$ \\
\hline $\begin{array}{l}\text { If you are traveling to a country where hepatitis B is common, try to get all the } \\
\text { shots before you go }\end{array}$ & $136(85.5)$ & $17(10.7)$ & $6(3.8)$ \\
\hline Health care professionals should receive hepatitis B vaccination & $141(88.7)$ & $7(4.5)$ & $6(3.8)$ \\
\hline Encourage the family members and other close personal contacts to get tested & $147(92.3)$ & $4(2.5)$ & $7(4.5)$ \\
\hline $\begin{array}{l}\text { Collaborations with other health professionals, especially trained nurses, dietitians, } \\
\text { and hepatologists are very important tools for care of patients with HBV. }\end{array}$ & $140(88.1)$ & $7(4.5)$ & $12(7.6)$ \\
\hline I feel confident in dealing with patient who is HBsAg positive & $84(52.8)$ & $41(25.8)$ & $34(21.4)$ \\
\hline
\end{tabular}

\# Some physicians did not respond to all items; HBV- Hepatitis B virus.

in other parts of Saudi Arabia. This study has shown that, only $69(43.4 \%)$ physicians were able to interpret HBV seromarkers and only 67 (42.1\%) recognized the incubation period of HBV [13]. Also, 97 (61\%) of the physicians were unaware of the risk of HBV chronicity which is inversely related to age $[2,3,13]$. Attributable reasons could be inadequate training programs about HBV. Our findings are not dissimilar to those reported in a recently study carried out in Australia to evaluate the knowledge and educational needs of GPs about viral hepatitis [15]. The referred study has identified limitations in knowledge among GPs concerning certain aspects of viral hepatitis [15].

Health education is of crucial significance for persons with HBV $[6-9,11,13]$. Those individuals should be educated about the risk of transmission, needle exchange programs, condom use, and avoidance of sharing toothbrushes, razors, etc. $[11,13]$. It was interesting to find most of the physicians 142 (89.3\%) had interest to involve the family on education and management of HBV patients. As such, educational skills about HBV could optimize care and management of patients and increase the doctor-patient relationship $[1,4,6,7]$.

Hepatitis B is one of the most highly infectious diseases without seasonal distribution [6]. Our findings show a high rate of misconceptions regarding infectivity patterns of HBV. It was found, only 37 (23.3\%) physicians recognized that HBV could be an infectious agent in the environment and more than $45 \%$ were not aware of its transmission through needlestick which is $50-100$ times higher in comparison with HIV [2,3,6,13]. Misconceptions and confusion that persist among PHC physicians in these

Table 5 Knowledge of PHC physicians regarding HBV vaccine in relation to their years in practice

\begin{tabular}{|c|c|c|c|c|c|c|}
\hline \multirow[b]{2}{*}{ Question item regarding $\mathrm{HBV}$ vaccine $\neq$} & \multirow[b]{2}{*}{$\begin{array}{c}\text { Correct; } \\
\mathrm{n}=159(\%)\end{array}$} & \multicolumn{3}{|c|}{ Physicians' years in practice } & \multirow[b]{2}{*}{$\mathrm{X}^{2}$} & \multirow[b]{2}{*}{$P$ value } \\
\hline & & $\begin{array}{l}<10 \text { yrs. } \\
N=81(\%)\end{array}$ & $\begin{array}{l}10-20 \text { yrs. } \\
\mathrm{N}=52(\%)\end{array}$ & $\begin{array}{l}>20 \text { yrs. } \\
N=24(\%)\end{array}$ & & \\
\hline Is safe for people of all ages; (T) & $130(81.8)$ & $63(77.8)$ & $45(86.5)$ & $22(91.7)$ & 4.549 & 0.919 \\
\hline $\begin{array}{l}\text { Hepatitis B vaccine and other vaccines administered during the } \\
\text { same visit should be given at different injection sites; }(T)\end{array}$ & $119(74.8)$ & $63(77.8)$ & $40(76.9)$ & $16(66.7)$ & 8.706 & 0.368 \\
\hline $\begin{array}{l}\text { The duration of protection is at least } 15 \text { years and, based on } \\
\text { current scientific evidence, lifelong; ( } T \text { ) }\end{array}$ & $63(39.6)$ & $32(39.5)$ & $24(46.2)$ & $7(29.2)$ & 4.730 & 0.316 \\
\hline $\begin{array}{l}\text { The complete vaccine series induces protective antibody levels } \\
\text { in }>95 \% \text { of infants, children and young adults; (T) }\end{array}$ & $115(72.3)$ & $50(61.7)$ & $44(84.6)$ & $21(87.5)$ & 10.137 & 0.035 \\
\hline $\begin{array}{l}\text { Hepatitis B vaccine can be given safely together with any other } \\
\text { vaccine, and vice versa; (T) }\end{array}$ & $117(73.6)$ & $60(74.1)$ & $39(75)$ & $18(75)$ & 5.838 & 0.442 \\
\hline Pregnancy is a contraindication for use of this vaccine; (F) & $80(50.3)$ & $36(44.4)$ & $30(57.7)$ & $14(58.3)$ & 6.699 & 0.568 \\
\hline
\end{tabular}

$\ddagger H P V=$ Hepatitis $B$ virus, $T=$ true, $F=$ false. 
aspects could interfere with patients' education and the safety of household contacts $[2,6,13]$. The possible explanation could be that, during an undergraduate study the infectious diseases, such as HBV are given only a small share in comparison to other medical subjects. In addition, textbooks were the main source of knowledge among the physicians surveyed and most textbooks are not updated, all of these issues could contribute to a lack of knowledge about HBV.

The most effective method of preventing HBV is through vaccination [2,4-6,13]. Interestingly, the vast majority of the physicians believed that vaccination is the mainstay to address $\mathrm{HBV}$, and more than $81 \%$ of them recognized that the vaccine is safe for people of all ages $[2,6,13]$. Our crosssectional study has shown adequate knowledge among PHC physicians regarding modes of HBV transmission. For specific modes of transmission (for example hugging, sharing food, maternofetal, breast milk) there were misconceptions $[2-4,13]$. This might be due to the controversy of these issues and the lack of the solid evidence. It is observed that maternofetal transmission is the dominant route of $\mathrm{HBV}$ transmission in high prevalence endemic areas such as South-East Asia [16]. Breast-feeding seems to be an additional mode by which infants acquire HBV; however, the risk associated with breast-feeding is negligible compared with that of exposure to maternal blood and body fluids at birth $[6,16,17]$.

In the area of follow-up, we found 100 (62.9\%) physicians suggested it is more appropriate for $\mathrm{CHB}$ patients with [HBeAg-ve, liver enzymes within normal limits] to be followed in the primary care. Whereas, nearly all the participants 150 (94.3\%) reported it is more appropriate for those with ( $\mathrm{HBeAg}+$ ve, elevated liver enzymes) to be referred to the specialists. Our findings are in agreement with several international strategies regarding prevention, care, and follow-up of HBV $[18,19]$. The referred strategies have demonstrated that patients in inactive carrier stage do not need treatment, because the progression of their liver disease is slow, if at all $[18,19]$. Only those patients who have $\mathrm{CHB}$ (active HBV replication with high viral load and ongoing necro-inflammation) qualify for treatment $[18,19]$.

This study has revealed that only minority of the PHC physicians 25 (15.7\%) considered that, PHCCs are a suitable places to manage HBV patients. Our findings and those internationally revealed that lack of investigation facilities in the PHCCs contribute further to poor management of HBV patients in the PHCCs [11]. It was found, the proportion of private physicians who considered PHCCs suitable places to manage $\mathrm{HBV}$ is more than that found among those governmental administered physicians $(25.0 \%$ vs $17.0 \%$; $<0.05)$. Attributable reasons could be adequate facilities at the private health care centers in comparison with that available in public PHCCs [11].
This study shows more suitable attitudes among PHC physicians toward HBV. It was found, 101 (63.7\%) physicians reported that, persons with $\mathrm{HBV}$ can participate in all activities including contact sports, and 119 (75.1\%) believed that they should not be excluded from the daycare or school participation and should not be isolated from other children. Also, 106 (66.7\%) physicians did not have concern on shaking hands and did not feel uncomfortable hugging a person who has HBV. Our findings are in agreement with those internationally which demonstrate that no evidence exists of HBV transmission by causal contact in the workplace, and $\mathrm{HBV}$ is not spread by kissing or hugging [13].

This study has revealed that the vast majority of the physicians were in favour to establish "Saudi guidelines for diagnosis and management of hepatitis B virus". This finding is in agreement with, and supports, those recommendations regarding management of $\mathrm{CHB}$ in resourcepoor countries. The referred recommendations revealed that guidelines for primary care physicians should be published and existing ones should be updated to keep physicians informed on changes in CHB management [1].

Strengths of this study including a high response rate (88.3\%), also, targeting PHC physicians that have been involved as a "gatekeepers" to the primary protective and curative health services, moreover, to the best of our knowledge, no similar study has been carried out among PHC physicians in Saudi Arabia. Despite of the study findings, we acknowledge its limitations, actually all the information are reported which may not be reflective of the actual situation in the primary care, also, all the questions in the questionnaire are close-ended which may hinder some important points on knowledge and practice of the participating physicians.

In conclusion, suitable attitudes with lack of knowledge were found and practice of PHC physicians regarding $\mathrm{HBV}$ appears inappropriate among the majority of PHC physicians in Al Jouf province of Saudi Arabia. This may be due to lack of structured training programs concerning $\mathrm{HBV}$. A well planned CME programs must be conducted to increase their knowledge and correct erroneous ideas regarding HBV. PHCCs should be technically supported to facilitate the diagnosis of HBV. Further studies are also required to identify other factors underlining the less than optimal preventive and management of $\mathrm{HBV}$ in the primary care setting.

\section{Competing interests \\ There is none to declare.}

Received: 27 November 2013 Accepted: 2 May 2014

Published: 9 May 2014

\section{References}

1. Nwokediuko SC: Chronic hepatitis B: management challenges in resource-poor countries. Hepat Mon 2011, 11:786-793. 
2. Gujral H, Collantes RS: Understanding viral hepatitis: a guide for primary care. Nurse Pract 2009, 34:23-31.

3. Wilkins T, Zimmerman D, Schade RR: Hepatitis B: diagnosis and treatment. Am Fam Physician 2010, 81:965-972.

4. Leung CM, Wong WH, Chan KH, Lai LS, Luk YW, Lai JY, Yeung YW, Hui WH: Public awareness of hepatitis B infection: a population-based telephone survey in Hong Kong. Hong Kong Med J 2010, 16:463-469.

5. Causse X, Delaunet A, Si Ahmed SN: Anaes practice guidelines for vaccination against hepatitis $B$ virus: impact on general practitioners. Gastroenterol Clin Biol 2009, 33:1166-1170.

6. Abedi F, Madani H, Asadi A, Nejatizadeh A: Significance of blood-related high-risk behaviors and horizontal transmission of hepatitis $B$ virus in Iran. Arch Virol 2011, 156:629-635.

7. Mohamed R, Desmond P, Suh DJ, Amarapurkar D, Gane E, Guangbi Y, Hou JL, Jafri W, Lai CL, Lee CH, Lee SD, Lim SG, Guan R, Phiet PH, Piratvisuth T, Sollano J, Wu JC: Practical difficulties in the management of hepatitis B in the Asia-Pacific region. J Gastroenterol Hepatol 2004, 19:958-969.

8. Tsai N: Diagnosis and management of chronic hepatitis B in the primary care setting. Postgrad Med 2006, 119:28-36.

9. Mostert MC, Richardus JH, De Man RA: Referral of chronic hepatitis B patients from primary to specialist care: making a simple guideline work. J Hepatol 2004, 41:1026-1030.

10. Dev A, Nguyen JH, Munafo L, Hardie E, lacono L: Chronic hepatitis B - a clinical audit of GP management. Aust Fam Physician 2011, 40:533-538.

11. Peksen Y, Canbaz S, Leblebicioglu H, Sunbul M, Esen S, Sunter AT: Primary care physicians' approach to diagnosis and treatment of hepatitis B and hepatitis C patients. BMC Gastroenterol 2004, 4:1-6.

12. Alrowaily MA, Abolfotouh MA, Ferwanah MS: Hepatitis B virus seroprevalence among pregnant females in Saudi Arabia. Saudi $J$ Gastroenterol 2008, 14:70-72.

13. Weinbaum CM, Williams I, Mast EE, Wang SA, Finelli L, Wasley A, Neitzel SM, Ward JW, Centers for Disease Control and Prevention (CDC):

Recommendations for identification and public health management of persons with chronic hepatitis B virus infection. MMWR Recomm Rep 2008, 57:1-20.

14. Veldhuijzen IK, Mostert MC, Niesters HG, Richardus JH, De Man RA: Accuracy of a referral guideline for patients with chronic hepatitis B in primary care to select patients eligible for evaluation by a specialist. Gut 2007, 56:1027-1028

15. Guirgis M, Yan K, Bu YM, Zekry A: General practitioners' knowledge and management of viral hepatitis in the migrant population. Intern Med J 2012, 42:497-504.

16. Sinha S, Kumar M: Pregnancy and chronic hepatitis B virus infection. Hepatol Res 2010, 40:31-48.

17. Pronczuk J, Moy G, Vallenas C: Breast milk: an optimal food. Environ Health Perspect 2004, 112:A722-A723.

18. Aggarwal $R$, Ranjan P: Preventing and treating hepatitis B infection. BMJ 2004, 329:1080-1086.

19. Gupta S, Altice FL: Hepatitis B virus infection in US correctional facilities: a review of diagnosis, management, and public health implications. J Urban Health 2009, 86:263-279.

\section{doi:10.1186/1756-0500-7-288}

Cite this article as: Al-Hazmi: Knowledge, attitudes and practice of primary health care physicians towards hepatitis B virus in Al-Jouf province, Saudi Arabia. BMC Research Notes 2014 7:288.

\section{Submit your next manuscript to BioMed Central and take full advantage of:}

- Convenient online submission

- Thorough peer review

- No space constraints or color figure charges

- Immediate publication on acceptance

- Inclusion in PubMed, CAS, Scopus and Google Scholar

- Research which is freely available for redistribution 